to its value as a remedial agent in the treatment of this class of affections.

Entcritis of Infancy. - While simple, uncomplicated enteritis is not a frecuent disease of infancy, yet it occurs occasionally, and is always of serious import at this tender age. Enteritis is manifested by the presence of slight fever, moderate diarrhoea, prostration, and paroxysms of violent spasmodic, nauseating and depressing pains in the abdomen, occurring particularly one or two hours after taking nourishment. During these attacks the pulse becomes frequent and feeble, the surface and extremities cold and often livid. Relief only comes after the passage of the contents of the intestines through the diseased duodenum, jejunum and ileum. The severe parox ysms of pain do not occur usually until the contents of the stomach have escaped from the organ into the small intestines.

Enteritis is invariably accompanied with loss of appetite and impraired cligestion. Nausea and vom iting in a more or less degree are usually present. Consequently the tendency to emaciation and reduc. tion of strength are marked. In the treatment of this affection I have found the following formula more useful than any other:

B Mucilag. acac.................... f

Aq. menth. pip.................. sis

Ol. terebinth $\ldots \ldots \ldots \ldots \ldots \ldots \ldots \ldots \ldots \ldots$, gttxii

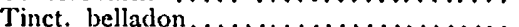

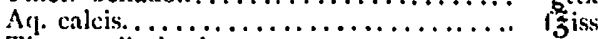

Tinct. opii. deod.................... gttx $\mathrm{M}$

Sig. - A teaspoonful for an infant one year okl every three or four hours.

As an adjuvant to the curpentine treatment in the painful affections of the intestines and stomach of infants, the belladonna has given me much satisfaction, and more particularly when the discharges are frequent.

Unclassified Painful Functional Affections of the Stomach and Intestines of Infants. - Infants which subsist on cow's milk and vegetable food principally, are liable to frequent attacks of pain and discomfort from irritations of the alimentary canal arising from imperfect, slow and tedious digestion, which may interfere seriously with the health and growth of the subject. These attacks may be purely of a functional character, or partake of a mild catarrhal nature, with slight fever. The intestinal discharges in these cases usually present an unhealthy appearance and are often extremely offensive, indicating a state of fermentation and putrefaction. The stimulant and carminative virtues of the turpentine, united with its antiseptic and anodyne properties, render the remedy peculiarly appropriate to this class of cases, particularly when combined with lime water and minute doses of carbolic acid.

In the class of cases treated of in this paper the oil of turpentine, as a remedial agent, is not presented as a sine qua non, but as a valuable agent to fill a place, and as an effective means of coöperating with other treatment for the relief of the many aggravated, painful and difficult affections of the gastro-intestinal canal of infants.

\section{TRANSPLANTATION OF CONJUNCTIVA FROM THE RABBIT. ${ }^{\prime}$}

BY EUGENE: SMITH, M.D.,

PROFHSSOR OF OYHTHALMOLOGY AND OTOLOGY IN DHTROIT COLIRGH OF MILDICINR,

It is not my intention to go into the history of transplantation of conjunctiva from rabbit to man, but simply to report a successful case, and the method followed. Allow me to premise, however, by saying that in the winter of $1873-4 \mathrm{I}$ saw De Wecker, of Paris, make the operation wherein he placed the conjunctiva, after removal from the rabbit, on a microscope slide over a tumbler of hot water to keep) it moist and warm before transplanting.

In $188 \mathrm{I}$, at the Intemational Medical Congress in London, which I had the honor to attend as a delegate from this Association, Dr. Dufour, of Iausanne, reported several cases, in two of which he adopted the method followed by De Wecker. The same year-188I-it was my good fortune to assist Dr. Wolfe, of Glasgow, in a successful case, in which, instead of using hot water, he placed the conjunctiva to be transplanted on the back of his hand, transporting it in that way to the patient's eye. This method was so simple in comparison that it is the one I have since adopted in two cases, only one of which was a success.

Mr. S. F., at. 26, was burned in the right eye with molten iron in September, 1885. He consulted me several weeks after the injury, at which time the upper and lower lids were attached to the inner half of the eyeball, the cornea being covered at its inner two-thirds. There was still a great deal of inflammatory reaction, and I advised postponement of operative procedure.

On January 25, 1886, about five months after the injury, I transplanted conjunctiva after the method of Wolfe, as described by him in the Annales d' Ocwlistique for September-October, I 881 , in his report of the case in which 1 assisted. My operation was made in the presence of the class of the Detroit College of Medicine.

It is not an easy task to remove so thin a menbrane as the conjunctiva and transplant it. The moment it is dissected it rolls upon itself and it is nearly inpossible to recognize the epithelial surface again. Sutures even do not prevent this tendency to roll up. For the purpose of recognizing the epithelial surface, three or four sutures are placed in the conjunctiva before it is dissected from the rabbit, the suture being long and the needles left in situ for use in grafting. Dr. Wolfe suggested and practices placing the conjunctiva on the back of the left hand, where it adheres and dries after being spread out. A little warm water suffices to moisten the conjunctiva and make its removal from the hand easy, when the eye is made ready for its reception.

The difficulty in holding the lid everted is overcome by passing three sutures through the border of the lid, with the ends of which the lid is controlled and kept in the required position. By this means

1 Read in the Section on Ophthalnology, Otology and Jaryngology, at the 'I hirty-Seventh Annual Mecting of the American Medical Associ- 
the annoyance of having the lid fly back just at the critical moment is avoided. From four to six sutures are all that are necessary to maintain the graft in position. In my case I tied the sutures so tight that they came out the third or fourth day without assistance. This is my habit with conjunctival sutures in general.

For the success of this case I feel indebted to Dr. Wolfe, and I have do doulst that if his precepts be followed by others more successful cases will be reported, and the operation become one of the regularly recognized operations, rather than a curiosity in ophthalmic surgery.

219 West Fort Street, Detroit, Mich.

\section{CHLOROFORM AS AN ANASTHETIC.}

I3Y T. J. HUTTON, M. D̀.,

OF PRRGUS HALLS, MINN.

PORMKRLY RRSEDTNT HIYSICIAN IN THR LONG ISLAND COLLLGR HOSPITAL, AND IN THE HKIGHAM HAII. ASYLUM.

While interne in the Long Island College Hospital fifteen years ago I had many cxcellent tutors; taken all in all the faculty as a whole seemed to me the personification of wisclom and professional enthusiasm. On one point, however, there was a serious breach of harmony: one used chloroform, one ether, another a mixture of the two, with or without alcohol, etc. On entering upon private practice, I chose chloroform as my anesthetic, and have now used it exclusively for fifteen years. Never, except in consultations, when I always defer to the preference of counsel, have I used any other anasthetic than chloroform.

In discussing this subject there are three questions which should be answered: 1. How often have I administered chloroform to complete insensibility? 2. Uncler what limitations? 3. With what results?

1. I have administered chloroform to the surgical tie degree of anasthesia about three thousand times; I have not kept a record of the cases, but I am sure that this rather falls short of than exceeds the truth.

In the Schuylkill, Pennsylvania, coal region, where I spent the four and a half years subsequent to leaving hospital, the Fates and their congeners the Molly Maguires held high carnival. Mining accidents, er.tailing all degrees of mutilation, were of almost hourly occurrence; and bullet wounds were sufficiently frequent to keep one quite in practice in that interesting department of surgery. It was not a rare occurrence to administer an anesthetic to two or three patients daily. Although eleven years have passed since I left that interesting field of labor, I can still distinctly recall single days in which $I$ had three serious accidents to treat, each requiring an anæsthetic. During those four and a half years I must have administered chloroform at least fifteen hundred times; in the past eleven years certainly no less.

2. Under what limitations? I do not administer chloroform to every one; and a rule from which I rarely deviate is to administer from a dram to an ounce of brandy, or whiskey, a few minutes in advance-according to the age of the patient. I do not administer it to persons with serious organic ailments, nor to scrawny individuals whose midgety stock of vitality is taxed to its utmost in normal respiration. Whole forenoons are not spent in stethoscopic determinations of heart lesions; a rapid survey of the tout ensemble -heart, pulse, tongue, general appearance and recent history, determines the fitness or unfitness for chloroform. All subjects must by no means be free from Haw, but granted the necessary soundness, it is used for both sexes, for all ages, for all manner of operations. A child a few weeks old was operated on twice under chloroform, first for cieft palate, again for hare-lip. A woman aged 66 , subject to violent attacks of hystero-epilepsy, was reduced to insensibility by chloroform at least a score of times. It is always administered in the second stage of labor-to partial or complete insensibility, as the case may require-except in rapid or painless labors, or that the patient object. I remember but three who persistently objected, and all who took it once demanded it in subsequent deliveries. In a case of convul. sions before labor in a primipara, bleeding, croton oil and seclatives failing to arrest them, four pounds of chloroform, administered alternately during four clays and nights, stoppecl them. Convulsions began Monday; stopped 'Thursday. On the following Sunday a large healthy child was born. Mother and child doing well. I shall not wonder if this case prove unique in the quantity of chloroform administered. There are some further limitations to its use, which some may consider trifling, and perhaps unworthy of mention, but which I regard as the key to this question: First, I use Squibb's chloroform exclusively. Notwithstanding my familiarity with chloroform in general, I would still feel extremely chary were I conpelled to use any other manufacture. Secondly, I will not administer it with a patient's head elevated. Dentists have offered greatest seductions in this direction. Sent for by them I go to find patient all ready, sitting high up in chair. "You must place patient on lounge with head low as body or I shall not administer it" is my invariable, inflexible charge. Once a little lady sat thus waiting, who, though free from heart or other organic lesion, was as impressible as mercury-as electric as the famous fish. Her pulse ran i22. "Not for a million dollars, Mrs. C., would I give you chloroform," I said, and after a glass of stiff port the extracting proceeded without anesthetics. Thirdly, I will only administer it on my "rag," which is extemporized in five seconds on the spot. A piece of old sheet or shirt about $2 \frac{1}{2} \times 3$ inches and four or six folds in thickness is saturated with chloroform. After the stimulant is given this is held for the first whiff or two about four inches from the nose, then advanced to three, two, or one inch, and curved towards the nose, is so held until insensibility is obtained. It need scarcely be written that the patient's clothing, particularly the neck-gear, must be abundantly loose, and that a quiet, trustful, passive condition must be enjoined on the part of the patient; "now close your eyes-breathe in long and gently." Covering the back of the rag with a piece of pasteboard saves chloroform by preventing evaporation; and it will be readily seen that our rag permits of a free admixture 